\title{
School meals in French secondary state schools: do national recommendations lead to healthier nutrition on offer?
}

\author{
Mélanie Bertin ${ }^{1}$, Lionel Lafay ${ }^{1}$, Gloria Calamassi-Tran ${ }^{1}$, Jean-Luc Volatier ${ }^{2}$ and Carine Dubuisson ${ }^{1 *}$ \\ ${ }^{1}$ Human Exposure Factors Unit, French Agency for Food, Environmental and Occupational Health Safety (ANSES), \\ Maisons-Alfort, France \\ ${ }^{2}$ Risk Assessment Department, French Agency for Food, Environmental and Occupational Health Safety (ANSES), \\ Maisons-Alfort, France
}

(Received 30 July 2010 - Revised 27 April 2011 - Accepted 28 April 2011 - First published online 12 August 2011)

\section{Abstract}

To improve the dietary offering in schools, the French authorities published recommendations on nutrition in 1999, which were then revised in 2007. The aim of the present study was to assess the nutritional offering in secondary school meals and the extent to which the recommendations promote balanced nutritional offerings. In 2005, a national survey was conducted on a representative sample of secondary schools, either administrated by the Ministry of Education (ES) or the Ministry of Agriculture (AS). Information on school-catering organisation and twenty consecutive meals was collected from each of the 707 secondary schools surveyed. Nutritional composition was estimated according to the French food composition database. Univariate and multivariate analyses were used to investigate the impact of food-group frequency guidelines (FFG) on nutritional offering. It was found that 15 and $26 \%$ of ES and AS schools, respectively, had high compliance with the FFG, at lunch. Macronutrient content was unbalanced in ES school lunches in which $42 \cdot 8 \%$ lipids, $21.5 \%$ proteins and $35.7 \%$ carbohydrates contributed to the energy. Nevertheless, proper offerings in Fe, Ca and vitamin C content were observed. In addition, a lower offering in lipids and a higher offering in proteins, Ca, vitamin C and Fe were found when the FFG were applied $(P<0 \cdot 001)$. Similar results were found for AS schools. This paper confirms the effectiveness of FFG in providing nutritionally balanced school meals. However, others measures such as nutrition promotion and actions to improve children's food habits have to be introduced to make the recommendations more effective and easier to understand.

Key words: School meals: National guidelines: Healthy nutrition: France

From preschool to high school, $65.6 \%$ of French children aged between 3 and 17 years have lunch at school at least once a week, $71.5 \%$ of children in lower secondary schools and $64.4 \%$ in upper secondary schools ${ }^{(1)}$, and $4 \cdot 2 \%$ have dinner (i.e. internal students) ${ }^{(2)}$. In addition, the last French National Dietary Survey (INCA 2) showed that children aged 3-17 years consumed 33.6 and $31.1 \%$ of their daily energy intake at lunch and dinner, respectively ${ }^{(3)}$. Thus, school meals contribute widely to the dietary and nutritional intakes of schoolchildren in France. Furthermore, both childhood and adolescence are the periods during which food habits and preferences are acquired and settled ${ }^{(4-7)}$. In this context, it is necessary that schools offer balanced meals that help fulfil the nutritional requirements. Schools have to set an example, especially given the growing preoccupation with obesity among the general population and the need to teach children to adopt more healthy dietary behaviour ${ }^{(8,9)}$. In addition, when given the choice, students often prefer fatty and sweetened foods over fruit and vegetables ${ }^{(10)}$. Consequently, several countries have agreed on the importance of applying food policies at schools to improve the nutritional quality of food and beverages available on school premises (in cafeterias, vending machines or other convenience stores) ${ }^{(11,12)}$. Indeed, several studies have already pointed out the beneficial effect of such policies (restriction of competitive food items) on children's food consumption and choices at school ${ }^{(13,14)}$, even though they were sometimes not effective enough to guarantee balanced diets in school meals ${ }^{(15)}$.

In France, several reports on dietary intake in school meals drew attention to the issue of unbalanced nutrition and diet on offer $^{(16-19)}$. In 2007, the study group on catering and nutrition markets (Groupe d'Etude des Marchés de Restauration Collective et Nutrition, GEMRCN) revised its recommendations ${ }^{(20)}$, first published in $1999^{(21)}$, to help caterers improve

Abbreviations: AS, Ministry of Agriculture; ES, Ministry of Education; FFG, food-group frequency guidelines; GEMRCN, Groupe d'Etude des Marchés de Restauration Collective et Nutrition; INCA, French National Dietary Survey. 
the nutritional quality of meals served at school. This revision added two new nutritional objectives (restrict total sugar intake, especially in desserts, and achieve a more balanced intake of fatty acids) to the original ones (reduce fat intakes and increase fibre, $\mathrm{Ca}$ and $\mathrm{Fe}$ intakes). To reach these nutritional objectives, the GEMRCN proposed fifteen food-group frequency guidelines (FFG) based on twenty meals (either on twenty successive lunches or twenty successive dinners), which were better described and generally more restrictive than the 1999 guidelines (see Table S1 of the supplementary material, available online http://www.journals.cambridge. org/bjn).

Further to the second National Nutrition and Health Programme $^{(22)}$, these FFG are about to become compulsory instead of simply being recommended. With the advent of this new legislation on school meal composition, it is important to ensure that these guidelines do actually lead to healthier meals by bringing the nutritional amounts served in line with the national nutritional requirements.

Given this background, this article (1) describes both the compliance of nutrients on offer and FFG in secondary school meals and (2) assesses FFG with respect to their effectiveness and relevance to get a balanced nutritional offering.

\section{Methods}

\section{Subjects}

The present study is based on a cross-sectional survey carried out on a representative sample of 1440 French lower and upper secondary state schools (i.e. 10- to 18-year-old children) from November 2005 to April 2006. The methodology has been described elsewhere ${ }^{(18)}$. Briefly, the schools were selected from two independent samples. The first sample included 1200 lower and upper secondary schools from France's mainland and overseas departments, randomly selected from among the 7000 secondary schools administrated by the Ministry of Education (ES) and having a cafeteria. The second sample included the 240 upper secondary schools administrated by the Ministry of Agriculture (AS). To ensure national representativeness of the sample, we randomly selected the 1200 ES schools by a balanced sampling design, based on four controlled variables (geographical location, school size and type, size of urban area and location in a deprived area or not).

After validation of questionnaire and verification of a minimum of fifteen meals returned, 707 schools were finally retained for statistical analysis. In this sample, 570 schools were administrated by the ES and 137 schools were administrated by the AS. Furthermore, of the final sample of 707 schools, 270 had boarding facilities.

\section{Measurements}

Every school was asked to fill out a questionnaire on its catering service management and the implementation of the guidelines, and was requested to enclose all menus (lunches and dinners) proposed during the last twenty school days.
The menus consisted of a list of the foods and dishes served by courses (starters, main dishes, side dishes, dairy products and dessert) during twenty successive days. However, information about the amounts of foodstuffs provided was not collected. Thereby, we used the adequate serving size recommended by the GEMRCN, according to the food characteristics and courses that were established to help caterers with their menu elaboration to match the recommendations.

First, the traditional French courses (i.e. starter, main dish, side dish, dairy product, dessert) were counted and identified for all the 22409 menus received (16893 lunches and 5516 dinners). Then, the food items recorded were allocated a nutritional composition in accordance with the French food composition database: CIQUAL ${ }^{(23)}$. When food items met the specifications for meal courses and nutritional composition, they were assigned to one or more of the fifteen food groups defined by the guidelines (see Table S1 of the supplementary material, available online http://www. journals.cambridge.org/bjn). Non-described 'cheese' and 'yogurts' (69.9\% at lunch and $73.5 \%$ at dinner) were randomly assigned, or not, to a particular food group after taking into account the statistical distribution observed in the remaining and clearly described cheese and yogurts. The number of menus sent could differ from one school to another (sixty-four schools sent fifteen to twenty meal sets and 643 schools sent twenty or more meal sets), and most of the menus were free-choice menus. Thus, to enable comparisons with the guidelines, the FFG observed in school meals were related to a set of twenty meals, according to the following formula:

\section{( $\Sigma_{\text {meals }}$ food stuffs corresponding to the food-groupdefinition/ \\ $\Sigma_{\text {meals }}$ all food stuffs corresponding to the courses included}

in the food-group definition $) \times(20 \times$ number of courses

included in thefood-group definition)

Calculation example: Estimation of a school adequacy to the FFG 'fried products $\geq 15 \%$ of lipids'.

This particular FFG is to apply to main courses and side dishes (two possible courses).

If a school returned twenty single menus including twenty starters, twenty main courses, twenty side dishes, twenty desserts, in which ten menus proposed fried products at the main course and ten menus proposed fried products at the side dish, the adequacy to the FFG 'fried products $\geq 15 \%$ of lipids' would be equal to: $((10+10) /(20+20)) \times(20 \times 2)=20$. The school would have served twenty times products from the FFG 'fried products $\geq 15 \%$ of lipids' on twenty meals.

If the school returned fifteen single menus only, in which fried products were also served ten times at the main course and ten times at the side dish, the adequacy to the FFG 'fried products $\geq 15 \%$ of lipids' would be equal to $(10+10) /(15+15)) \times(20 \times 2)=26 \cdot 7$.

The school would have served $26 \cdot 7$ times products from the FFG 'fried products $\geq 15 \%$ of lipids' on twenty meals. 
The number of FFG met by each school was calculated as the sum of each FFG, followed or not ( 0 or 1 ), considering the meal type (lunch or dinner) separately. The schools' compliance regarding the recommendations was estimated both quantitatively (on a scale from 0 to 15 for the FFG met) and qualitatively through a three-class variable: low compliance with the recommendations (six or less out of fifteen FFG followed), medium (from seven to eight out of fifteen) or high (nine or more out of fifteen).

Nutrient amounts and macronutrient contributions to energy were obtained by the addition of nutritional amounts in each course of the meal: starter + main dish + side dish $(+$ dairy products $)+$ desserts. Dairy products were considered to be a single course in the case of a five-course menu, and were included in the desserts in the case of four-course menu. When free-choice menus were offered to the students, a mean of nutrient amounts was first estimated by course and then added to the means of other courses of the meal.

Finally, a mean of nutritional amounts was calculated per school, considering lunch and dinner separately, and compared to the national nutritional requirements when they were available. On average, a lunch meal must provide between 11 and $15 \%$ of energy from proteins, 50 and $55 \%$ from carbohydrates, 30 and 35\% from lipids, at least 300$400 \mathrm{mg} \mathrm{Ca}$ and $4-7 \mathrm{mg} \mathrm{Fe}^{(22)}$. No information on the amounts of vitamin $\mathrm{C}$ required has been provided for lunches. The requirements were set at $35-50 \mathrm{mg}$ as the requirements for $1 \mathrm{~d}$ are estimated at $110 \mathrm{mg}$ for teenagers.

\section{Statistical analysis}

All analyses were carried out using the Statistical Analysis System, version 9.1 (SAS Institute, Inc., Cary, NC, USA). The representativeness of the final samples was tested according to the controlled variables used for the balanced sampling design: geographical location, school size and type, size of urban area and location in a deprived area or not. Only a little deviation regarding the geographical location was observed. Therefore, a weighting coefficient was calculated by the ratio method of the CALMAR macro ${ }^{(24)}$ to ensure the national representativeness of the final sample.

The number of meal courses (four or five) and type of menu (free choice, guided choice, no choice (unique menu)) were considered as possible confounding variables, as they have been shown to be associated with the level of implementation of frequency guidelines and the nutritional amounts in the meals ${ }^{(25)}$. Indeed, five components and free-meal choice (often associated with five components) were found to be related to an increase in nutritional amounts (results not shown). The mean nutrient amounts provided by school meals were compared between ES and AS schools and lunch and dinner, using a $t$ test. The relationships between nutrient amounts (i.e. lipids, proteins, total sugars, $\mathrm{Ca}, \mathrm{Fe}$ and vitamin $\mathrm{C}$ and energy) and the compliance with their corresponding FFG (i.e. the FFG that aimed at the nutrient reduction or increase) and the overall recommendations adequacy were tested using ANOVA after controlling for the two adjustment variables. The level of significance used was
$P<0 \cdot 05$. ES and AS schools were studied separately because of their different sampling design.

\section{Results \\ Compliance of meal food composition with the recommendations}

Table 1 shows the proportion of schools meeting each FFG and their distribution according to the three levels of compliance defined.

Recommendations were less followed at dinnertime $(P<0.05)$ for both ES and AS schools, with 44.8 and $60 \cdot 2 \%$ of ES and AS, respectively, having a low compliance level, 47.4 and $33.9 \%$ an intermediate one, and 7.7 and $5.9 \%$ a high level. ES schools followed more guidelines at dinner than AS schools, whereas the contrary was observed for lunches $(P<0 \cdot 05)$. According to the three levels of compliance defined, 32.9 and $28.2 \%$ of the ES and AS schools, respectively, had a low level for lunches, $52 \cdot 1$ and $45 \cdot 5 \%$ an intermediate level, and 15.0 and $26.3 \%$ a high level. Food groups consisting of high-fat starters, fried products, raw fruits, vegetables, dairy products and starchy foods were well offered whereas food groups consisting of highly sweetened desserts, main courses, preparations, cheese, meat and fish were insufficiently offered in school meals.

\section{Nutrient amount offered in school lunches and dinners}

The mean meal nutrients on offer and macronutrient contribution to energy are shown in Table 2. A significant effect of the type of meals (lunch or dinner) and of the types of school was observed for several nutrient offerings. Lipid, protein and carbohydrate contributed respectively to $42.8,21.5$ and $35.7 \%$ of energy offering at lunch in ES schools. Similar proportions were noted for dinners in ES schools and for lunches and dinners in AS schools. Average offerings of vitamin $\mathrm{C}, \mathrm{Fe}$ and $\mathrm{Ca}$ matched the estimated average requirements with 42.2 and $40.6 \mathrm{mg}$ vitamin $\mathrm{C}, 5.4$ and $5.6 \mathrm{mg} \mathrm{Fe}$, and 338.3 and $355.9 \mathrm{mg} \mathrm{Ca}$, respectively, in ES and AS schools at lunch.

\section{Impact of food-group frequency guidelines on nutrient offering}

The impact of each FFG on its respective nutrient offering is shown in Table 3. In general, the observations confirmed that the FFG had been effective in adjusting the nutrient amount offered.

The impact of the FFG on nutrient offering was generally greater at lunch and for ES schools. No significant impact was observed for the food groups that were either fully followed (fried products, desserts with $>15 \%$ of lipids) or poorly followed (desserts $<15 \%$ of lipids). However, they did decrease the amounts of lipids and total sugars (desserts) offered in the meals.

The lipid offering was significantly lower when the starters with $>15 \%$ of lipids were limited by the schools, as suggested 
Table 1. Prevalence of schools meeting the food-group frequency guidelines for twenty meals, according to the type of meal and the ministry in charge of the schools* (Percentages and $95 \%$ confidence intervals)

\begin{tabular}{|c|c|c|c|c|c|c|c|c|}
\hline \multirow[b]{3}{*}{ Food group } & \multicolumn{4}{|c|}{ Lunch ( $n$ 707) } & \multicolumn{4}{|c|}{ Dinner $(n 270)$} \\
\hline & \multicolumn{2}{|c|}{ ES schools $(n 570)$} & \multicolumn{2}{|c|}{ AS schools $(n 137)$} & \multicolumn{2}{|c|}{ ES schools $(n 137)$} & \multicolumn{2}{|c|}{ AS schools ( $n$ 133) } \\
\hline & $\%$ & $95 \% \mathrm{Cl}$ & $\%$ & $95 \% \mathrm{Cl}$ & $\%$ & $95 \% \mathrm{Cl}$ & $\%$ & $95 \% \mathrm{Cl}$ \\
\hline \multicolumn{9}{|l|}{ Percentage of compliance with the food-group frequency guidelines } \\
\hline Starters containing $15 \%$ fat or more & $60 \cdot 9$ & $56 \cdot 9,64 \cdot 9$ & $40 \cdot 7$ & $32 \cdot 5,49 \cdot 0$ & $76 \cdot 1$ & $68 \cdot 9,83 \cdot 2$ & $63 \cdot 1$ & $54.9,71.3$ \\
\hline Fried products containing $15 \%$ fat or more & $100 \cdot 0$ & $100 \cdot 0,100 \cdot 0$ & $100 \cdot 0$ & $100 \cdot 0,100 \cdot 0$ & $100 \cdot 0$ & $100 \cdot 0,100 \cdot 0$ & $100 \cdot 0$ & $100 \cdot 0,100 \cdot 0$ \\
\hline Main courses with protein:fat ratio $<1$ & $22 \cdot 2$ & $18 \cdot 8,25 \cdot 6$ & 34.6 & $26 \cdot 6,42 \cdot 6$ & 8.9 & $4 \cdot 2,13 \cdot 7$ & $6 \cdot 3$ & $2 \cdot 2,10 \cdot 4$ \\
\hline Red meat, not minced & $17 \cdot 7$ & $14 \cdot 6,20 \cdot 9$ & $54 \cdot 1$ & $45 \cdot 8,62 \cdot 4$ & 14.4 & $8.5,20.2$ & 1.5 & $0.6,3.6$ \\
\hline Fish with a protein:fat ratio $\geq 2$ & $16 \cdot 4$ & $13 \cdot 3,19 \cdot 4$ & 14.7 & $8 \cdot 8,20 \cdot 7$ & 6.6 & $2 \cdot 5,10 \cdot 8$ & $2 \cdot 3$ & $0.3,4 \cdot 8$ \\
\hline Preparations including $<70 \%$ meat, fish, eggs or cheese & $12 \cdot 2$ & $9.5,14.9$ & $42 \cdot 7$ & $34 \cdot 4,51 \cdot 0$ & $6 \cdot 2$ & $2 \cdot 1,10 \cdot 2$ & $2 \cdot 8$ & $0.0,5.5$ \\
\hline Raw fruit and vegetables & $74 \cdot 1$ & $70 \cdot 5,77 \cdot 7$ & $62 \cdot 2$ & $54 \cdot 0,70 \cdot 3$ & $52 \cdot 0$ & $43 \cdot 6,60 \cdot 4$ & $48 \cdot 6$ & $40 \cdot 2,57 \cdot 1$ \\
\hline Starchy foods & $78 \cdot 8$ & $75 \cdot 4,82 \cdot 1$ & $76 \cdot 1$ & $69.0,83.3$ & $90 \cdot 6$ & $85 \cdot 7,95 \cdot 5$ & $79 \cdot 0$ & $72 \cdot 1,85 \cdot 9$ \\
\hline Cooked vegetables (>50\%) & 61.5 & $57 \cdot 5,65 \cdot 5$ & $62 \cdot 0$ & $53 \cdot 9,70 \cdot 1$ & $43 \cdot 6$ & $35 \cdot 3,51.9$ & $56 \cdot 7$ & $48 \cdot 3,65 \cdot 2$ \\
\hline Desserts containing raw fruit & 89.9 & $87 \cdot 4,92 \cdot 4$ & $88 \cdot 1$ & $82 \cdot 7,93.5$ & $90 \cdot 2$ & $85 \cdot 2,95 \cdot 2$ & $89 \cdot 1$ & $83 \cdot 8,94.4$ \\
\hline Cheeses containing $150 \mathrm{mg} \mathrm{Ca} /$ portion & $8 \cdot 2$ & $6 \cdot 0,10.5$ & $22 \cdot 6$ & $15 \cdot 6,29 \cdot 6$ & 17.9 & $11 \cdot 5,24 \cdot 3$ & 24.4 & $17 \cdot 1,31 \cdot 7$ \\
\hline Cheeses containing 100 to $150 \mathrm{mg} \mathrm{Ca} /$ portion & $6 \cdot 3$ & $4 \cdot 3,8 \cdot 3$ & $18 \cdot 2$ & $11 \cdot 7,24 \cdot 7$ & 3.8 & $0 \cdot 6,7 \cdot 1$ & $18 \cdot 7$ & $12 \cdot 0,25 \cdot 3$ \\
\hline Dairy products containing $100 \mathrm{mg} \mathrm{Ca}$ and $<5 \mathrm{~g}$ fat/portion & $76 \cdot 8$ & $73 \cdot 4,80 \cdot 3$ & $63 \cdot 0$ & $54 \cdot 9,71 \cdot 1$ & $80 \cdot 3$ & $73 \cdot 7,87 \cdot 0$ & 63.7 & $55.6,71.9$ \\
\hline Desserts containing $15 \%$ fat and $>20 \mathrm{~g}$ total sugar/portion & $82 \cdot 4$ & $79 \cdot 3,85 \cdot 5$ & 89.9 & $84.8,94.9$ & 88.4 & $83 \cdot 0,93 \cdot 7$ & 89.7 & $84.5,94 \cdot 8$ \\
\hline Desserts containing $<15 \%$ and $>20 \mathrm{~g}$ total sugar/portion & 1.1 & $0.2,1.9$ & 1.2 & $0.6,3.0$ & 0.0 & $0.0,0.0$ & 0.7 & $0.7,2 \cdot 0$ \\
\hline \multicolumn{9}{|l|}{ Level of compliance with all food-group frequency guidelines } \\
\hline Low level $(0-6)$ & $32 \cdot 9$ & $29 \cdot 0,36 \cdot 8$ & $28 \cdot 2$ & $20 \cdot 7,35 \cdot 7$ & $44 \cdot 8$ & $36 \cdot 5,53 \cdot 1$ & $60 \cdot 2$ & $51.9,63.5$ \\
\hline Medium level $(7-8)$ & $52 \cdot 1$ & $48 \cdot 0,56 \cdot 2$ & 45.5 & $37 \cdot 2,53 \cdot 8$ & 47.4 & $39 \cdot 0,55 \cdot 7$ & 33.9 & $25 \cdot 8,41.9$ \\
\hline High level $(9-15)$ & $15 \cdot 0$ & $12 \cdot 1,17 \cdot 9$ & $26 \cdot 3$ & $18 \cdot 9,33 \cdot 7$ & $7 \cdot 7$ & $3 \cdot 2,12 \cdot 1$ & 5.9 & $1.9,9.9$ \\
\hline
\end{tabular}

ES, general and vocational teaching; AS, agricultural teaching.
* Reading example: $60.9 \%$ of the ES schools and $40.7 \%$ of the AS schools met the guideline limiting starters with $15 \%$ of fat or more at lunch; 76.1 and $63.1 \%$ of ES and AS schools, respectively, met this guideline at dinner. 
in the recommendations. Following FFG for the main course with a protein:fat ratio $<1$ and desserts with $>15 \%$ lipids food groups also lowered the lipid amounts offered, even though the differences were not significant for dinner and AS schools.

Furthermore, a proper offering in red meats and preparations including more than $70 \%$ of eggs, meat or fish increased the protein amounts in the meals served. Amounts of $\mathrm{Ca}$, as well as amounts of lipids, were significantly higher when the guidelines related to cheese were met. However, suitable servings of dairy products decreased the offering in $\mathrm{Ca}$. In addition, a significant increase in vitamin $\mathrm{C}$ was noted when starters with raw vegetables and desserts with fruit were proposed according to the guidelines. This improvement was also observed with a greater offering in cooked vegetables in the side course, but only at dinner. Finally, a better offering in Fe was found when the FFG regarding red meat was followed, but the difference was significant only for ES lunches. The respect of the preparations including more than $70 \%$ eggs, meat or fish FFG showed to enhance Fe offering for ES schools only, at both lunches and dinners, whereas following FFG on fish did not increase the dietary Fe offering.

\section{Compliance with the overall food-group frequency guidelines on nutritional offering}

Table 4 presents the impact of the overall FFG on the different nutrients and energy offerings in school meals. Higher compliance regarding the overall recommendations is associated with a 'lower energy and lipids offering' (with a significant difference at lunch for both ES and AS schools). It was also shown that greater compliance with the FFG made it possible to increase the 'vitamin $\mathrm{C}$ and reduce the carbohydrate offering'.

\section{Discussion}

The main objective of the study was to identify the effectiveness of the dietary recommendations in enabling schools to achieve an adequate nutritional offering in school meals. The present study used data from the only national survey on school meals and catering in France. The large sample and national representativeness of the survey on school catering and meals served offered many advantages for estimating the effectiveness of the dietary recommendations in adjusting the nutritional offering of school meals.

Nevertheless, there are several limitations to the present study. First, the study design itself, which included only state schools. This limitation remained acceptable, as $78 \%$ of French pupils go to state schools. However, data on meals served in private schools should be collected in the future as they receive nearly $20 \%$ of the schoolchildren that eat at school. Moreover, the menus were collected only in autumn/winter, which did not take into account seasonal availability in some foods such as fruits and vegetables. Nevertheless, this does not invalidate the study results as the FFG were set up to be relevant throughout the year. Apart from that, after two reminders during the school year, the final response rate remained at $49 \%$, which matched the range of 
Table 3. Impact of the Groupe d'Etude des Marchés de Restauration Collective et Nutrition recommendations on nutrient amounts associated, considering the type of meal and ministry in charge of the schoolst

(Mean values and 95\% confidence intervals)

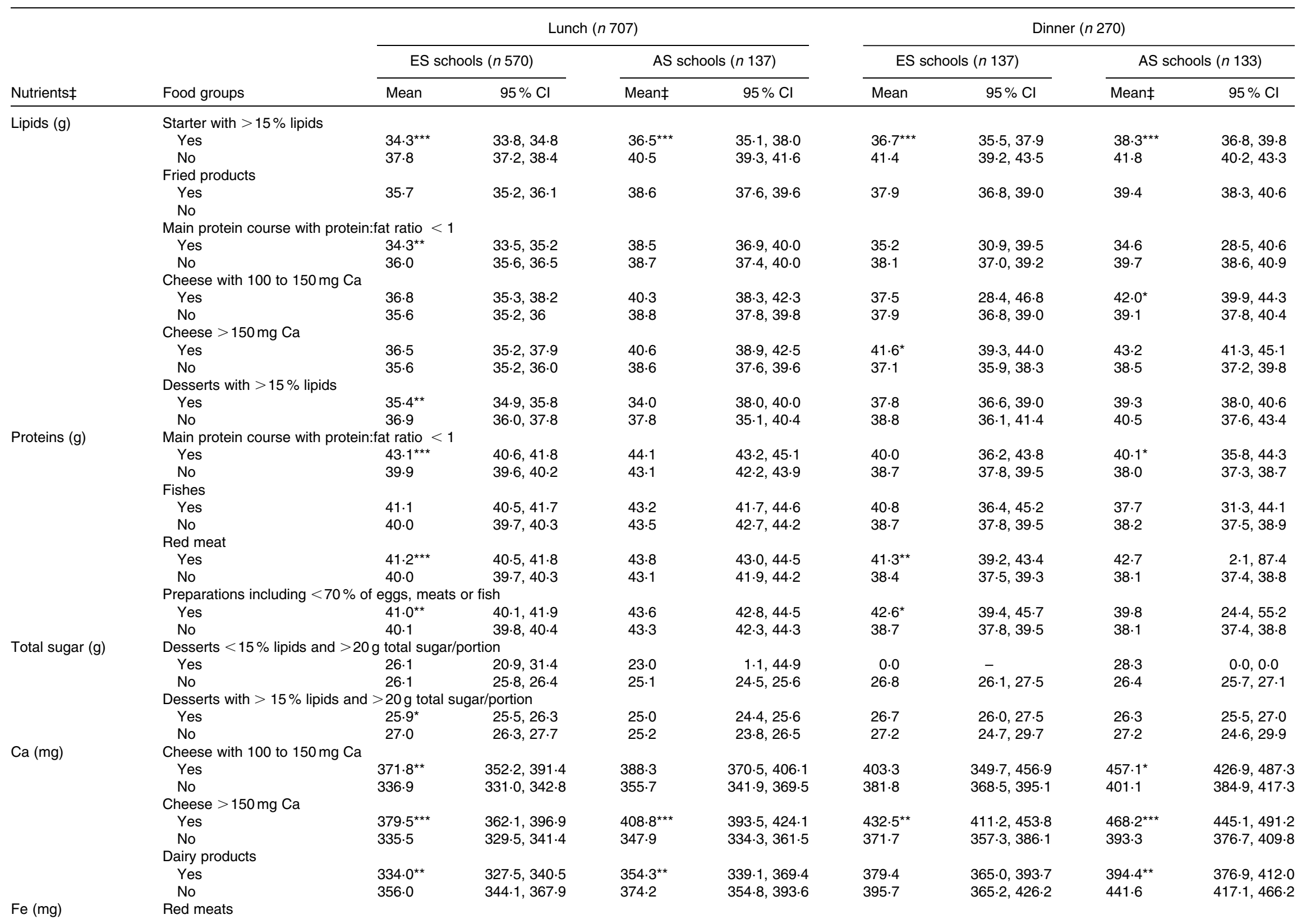


Table 3. Continued

\begin{tabular}{|c|c|c|c|c|c|c|c|c|c|}
\hline \multirow[b]{3}{*}{ Nutrients $\ddagger$} & \multirow[b]{3}{*}{ Food groups } & \multicolumn{4}{|c|}{ Lunch ( $n 707)$} & \multicolumn{4}{|c|}{ Dinner ( $n$ 270) } \\
\hline & & \multicolumn{2}{|c|}{ ES schools $(n 570)$} & \multicolumn{2}{|c|}{ AS schools $(n 137)$} & \multicolumn{2}{|c|}{ ES schools $(n 137)$} & \multicolumn{2}{|c|}{ AS schools ( $n 133)$} \\
\hline & & Mean & $95 \% \mathrm{Cl}$ & Mean $\ddagger$ & $95 \% \mathrm{Cl}$ & Mean & $95 \% \mathrm{Cl}$ & Mean‡ & $95 \% \mathrm{Cl}$ \\
\hline & Yes & $5 \cdot 5^{\star \star}$ & $5 \cdot 4,5 \cdot 7$ & $5 \cdot 7$ & $5 \cdot 5,5 \cdot 8$ & 5.5 & $5.1,5.9$ & $6 \cdot 1$ & $2.9,9.4$ \\
\hline & No & $5 \cdot 3$ & $5 \cdot 3,5 \cdot 4$ & 5.5 & $5 \cdot 3,5 \cdot 7$ & 5.4 & $5 \cdot 2,5.5$ & $5 \cdot 2$ & $5 \cdot 0,5 \cdot 3$ \\
\hline & Fishes & & & & & & & & \\
\hline & Yes & $5 \cdot 3$ & $5 \cdot 2,5 \cdot 4$ & $5 \cdot 6$ & $5 \cdot 4,5 \cdot 8$ & $5 \cdot 6$ & $4 \cdot 9,6 \cdot 3$ & $5 \cdot 1$ & $4 \cdot 4,5 \cdot 8$ \\
\hline & No & 5.4 & $5 \cdot 3,5 \cdot 4$ & $5 \cdot 6$ & $5 \cdot 5,5 \cdot 7$ & 5.4 & $5 \cdot 2,5.5$ & $5 \cdot 2$ & $5 \cdot 1,5 \cdot 3$ \\
\hline & Preparations & eggs, me & & & & & & & \\
\hline & Yes & 5.5 & $5 \cdot 3,5 \cdot 6$ & $5 \cdot 6$ & $5 \cdot 5,5 \cdot 8$ & 5.9 & $5 \cdot 4,6 \cdot 6$ & $5 \cdot 3$ & $2 \cdot 3,8 \cdot 0$ \\
\hline & No & 5.4 & $5 \cdot 3,5 \cdot 4$ & $5 \cdot 6$ & $5 \cdot 4,5 \cdot 8$ & 5.4 & $5 \cdot 2,5.5$ & $5 \cdot 2$ & $5 \cdot 1,5 \cdot 3$ \\
\hline \multirow[t]{9}{*}{ Vitamin C (mg) } & Starter with ro & & & & & & & & \\
\hline & Yes & $43 \cdot 9^{\star \star}$ & $43 \cdot 1,44 \cdot 8$ & $44 \cdot 3$ & $42 \cdot 2,46 \cdot 4$ & $45 \cdot 9^{\star \star}$ & $44.7,51 \cdot 2$ & 47.4 & $46 \cdot 6,54 \cdot 6$ \\
\hline & No & $37 \cdot 0$ & $35 \cdot 6,38.5$ & 34.4 & $31 \cdot 8,37 \cdot 1$ & $41 \cdot 1$ & $37 \cdot 2,42 \cdot 3$ & $42 \cdot 5$ & $38.2,43.5$ \\
\hline & Desserts with & & & & & & & & \\
\hline & Yes & $43 \cdot 5^{\star \star \star}$ & $42 \cdot 7,44 \cdot 2$ & $42 \cdot 6^{\star}$ & $40 \cdot 7,44.4$ & $48 \cdot 0$ & $43 \cdot 5,48 \cdot 3$ & $50 \cdot 6$ & $44 \cdot 8,50 \cdot 1$ \\
\hline & No & $35 \cdot 0$ & $33 \cdot 3,37 \cdot 3$ & 34.4 & $30 \cdot 3,38 \cdot 4$ & $39 \cdot 8$ & $35 \cdot 6,46 \cdot 7$ & $40 \cdot 8$ & $36 \cdot 7,48 \cdot 3$ \\
\hline & Cooked vege & & & & & & & & \\
\hline & Yes & $42 \cdot 2$ & $41 \cdot 3,43$ & $40 \cdot 8$ & $39 \cdot 0,42 \cdot 5$ & $43 \cdot 0^{\star \star \star}$ & $40 \cdot 9,45 \cdot 1$ & $41.9^{*}$ & $39.4,44.5$ \\
\hline & No & $42 \cdot 2$ & $40 \cdot 7,43 \cdot 7$ & $40 \cdot 3$ & $36.5,44 \cdot 1$ & $44 \cdot 8$ & $41 \cdot 3,48 \cdot 3$ & $50 \cdot 4$ & $45 \cdot 9,54 \cdot 8$ \\
\hline
\end{tabular}

ES, general and vocational teaching; AS, agricultural teaching.

Mean values were significantly different according to compliance or not with specific food-group frequency guidelines, tested using ANOVA adjusted on the type of menu and number of components: ${ }^{*} P<0.05 ;{ }^{* \star} P<0.01$; ${ }^{* * *} P<0.001$.

† Reading example: at lunch a meal served in ES schools provided on average $34.3 \mathrm{~g}$ lipids if they met the FFG 'Starter with $>15 \%$ lipids' and provided $37.8 \mathrm{~g}$ lipids if not.

₹ A relation between a particular nutrient and a specific FFG was studied if the nutrient was concerned by an FFG. For example: the amounts in Ca were analysed in relation to the FFG that were proposed to improved amounts of Ca the schools meals that are the FFG: cheese $>150 \mathrm{mg} \mathrm{Ca}$, cheese with 100 to $150 \mathrm{mg} \mathrm{Ca}$ and dairy products. 
Table 4. Nutrients and energy average offer following the overall food-frequency guideline adequacy (i.e. three levels of adequacy) $\dagger$ (Mean values and $95 \%$ confidence intervals)

\begin{tabular}{|c|c|c|c|c|c|c|c|c|c|c|c|c|}
\hline \multirow[b]{3}{*}{ Nutrients } & \multicolumn{6}{|c|}{ Lunch ( $n$ 707) } & \multicolumn{6}{|c|}{ Dinner ( $n$ 270) } \\
\hline & \multicolumn{3}{|c|}{ ES schools ( $n 570)$} & \multicolumn{3}{|c|}{ AS schools ( $n$ 137) } & \multicolumn{3}{|c|}{ ES schools ( $n$ 137) } & \multicolumn{3}{|c|}{ AS schools ( $n$ 133) } \\
\hline & Low & Medium & High & Low & Medium & High & Low & Medium & High & Low & Medium & High \\
\hline \multicolumn{13}{|l|}{ Energy $(\mathrm{kJ})$} \\
\hline Mean & $3225 \cdot 9^{* \star *}$ & $3109 \cdot 1$ & 3055.5 & $3323 \cdot 5^{\star \star}$ & $3259 \cdot 8$ & 3217.6 & 3331.4 & $3196 \cdot 6$ & $3244 \cdot 8$ & $3262 \cdot 8$ & 3214.6 & $3146 \cdot 0$ \\
\hline $95 \% \mathrm{Cl}$ & $3184 \cdot 1,3267 \cdot 8$ & $3076 \cdot 0,3142 \cdot 2$ & $2999 \cdot 0,3112 \cdot 5$ & $3155 \cdot 2,3491 \cdot 8$ & $3189 \cdot 1,3331 \cdot 0$ & $3120 \cdot 4,3314 \cdot 3$ & $3212 \cdot 5,3450 \cdot 3$ & $3104 \cdot 9,3287 \cdot 9$ & $3133 \cdot 0,3356 \cdot 1$ & $3173 \cdot 6,3351 \cdot 5$ & $3096 \cdot 6,3333 \cdot 1$ & $3030 \cdot 8,3260 \cdot 7$ \\
\hline \multicolumn{13}{|c|}{ Carbohydrates (g) } \\
\hline Mean & $67 \cdot 9^{\star}$ & 66.6 & $66 \cdot 3$ & 65.9 & 64.5 & 63.6 & $73 \cdot 2^{\star}$ & 68.5 & 70.1 & $66 \cdot 6$ & $67 \cdot 2$ & 62.7 \\
\hline $95 \% \mathrm{Cl}$ & $66 \cdot 8,69 \cdot 1$ & $65 \cdot 7,67.6$ & $64 \cdot 7,67 \cdot 8$ & $62 \cdot 5,69 \cdot 2$ & $62 \cdot 4,66 \cdot 6$ & $60 \cdot 9,66 \cdot 3$ & $70 \cdot 1,76 \cdot 3$ & $66 \cdot 1,71 \cdot 0$ & $63 \cdot 7,76 \cdot 4$ & $64 \cdot 1,69 \cdot 1$ & $64 \cdot 1,70 \cdot 3$ & $57 \cdot 7,67 \cdot 8$ \\
\hline \multicolumn{13}{|l|}{ Lipids (g) } \\
\hline Mean & $37 \cdot 5^{\star \star \star}$ & 35.1 & 33.5 & $40 \cdot 0^{\star \star \star}$ & $38 \cdot 3$ & 37.7 & 38.7 & 37.1 & 37.3 & $40 \cdot 1$ & 38.4 & 38.1 \\
\hline $95 \% \mathrm{Cl}$ & $36 \cdot 8,38 \cdot 2$ & $34.5,35 \cdot 7$ & $32 \cdot 4,34 \cdot 6$ & $37 \cdot 1,42 \cdot 8$ & $37 \cdot 1,39 \cdot 6$ & $35 \cdot 9,39 \cdot 4$ & $37 \cdot 0,40 \cdot 4$ & $35 \cdot 4,38.7$ & $33 \cdot 8,40 \cdot 8$ & $38 \cdot 5,41 \cdot 7$ & $35 \cdot 9,41 \cdot 0$ & $36 \cdot 1,40 \cdot 1$ \\
\hline \multicolumn{13}{|c|}{ Proteins (g) } \\
\hline Mean & $40 \cdot 3$ & 40.0 & $40 \cdot 8$ & $42 \cdot 6$ & 43.8 & 43.7 & 38.6 & 38.8 & 39.6 & 38.0 & 38.3 & 39.4 \\
\hline $95 \% \mathrm{Cl}$ & $39 \cdot 8,40 \cdot 8$ & $39 \cdot 6,40 \cdot 4$ & $39 \cdot 9,41 \cdot 6$ & $40 \cdot 6,44 \cdot 6$ & $43 \cdot 0,44 \cdot 6$ & $42 \cdot 7,44 \cdot 6$ & $37 \cdot 3,40 \cdot 0$ & $37 \cdot 6,40 \cdot 0$ & $38 \cdot 5,40 \cdot 8$ & $37 \cdot 0,38 \cdot 9$ & $37 \cdot 1,39 \cdot 5$ & $36 \cdot 4,42 \cdot 4$ \\
\hline \multicolumn{13}{|c|}{ Total sugar (g) } \\
\hline Mean & $26 \cdot 1$ & 26.0 & 26.5 & $23 \cdot 5^{\star \star}$ & $26 \cdot 0$ & $24 \cdot 1$ & 26.8 & $26 \cdot 3$ & 29.0 & $26 \cdot 1$ & 26.9 & $26 \cdot 0$ \\
\hline $95 \% \mathrm{Cl}$ & $25 \cdot 5,26 \cdot 6$ & $25 \cdot 5,26 \cdot 5$ & $25 \cdot 6,27 \cdot 4$ & $21 \cdot 8,25 \cdot 1$ & $25 \cdot 2,26 \cdot 7$ & $22 \cdot 9,25 \cdot 3$ & $25 \cdot 8,27 \cdot 9$ & $25 \cdot 2,27 \cdot 5$ & $27 \cdot 0,30 \cdot 9$ & $25 \cdot 1,27 \cdot 1$ & $25 \cdot 6,28 \cdot 1$ & $24 \cdot 2,27 \cdot 7$ \\
\hline \multicolumn{13}{|c|}{ Vitamin C (mg) } \\
\hline Mean & $41 \cdot 0$ & 42.5 & 43.6 & $34 \cdot 5^{\star \star}$ & 43.5 & $42 \cdot 1$ & $44 \cdot 3$ & 44.1 & 44.7 & $47 \cdot 0^{\star}$ & $42 \cdot 2$ & $51 \cdot 0$ \\
\hline $\begin{array}{l}95 \% \mathrm{Cl} \\
\mathrm{Ca}(\mathrm{mg})\end{array}$ & $39 \cdot 4,42 \cdot 5$ & $41 \cdot 4,43 \cdot 5$ & $\mathrm{Ca}(\mathrm{mg})$ & $31 \cdot 0,38 \cdot 0$ & $40 \cdot 9,46 \cdot 0$ & $38 \cdot 8,45 \cdot 3$ & $40 \cdot 1,48 \cdot 4$ & $41 \cdot 3,46 \cdot 8$ & $39 \cdot 7,49 \cdot 7$ & $43 \cdot 4,50 \cdot 6$ & $38 \cdot 3,45 \cdot 9$ & $46 \cdot 8,55 \cdot 1$ \\
\hline Mean & 336.2 & 338.3 & 343.2 & 337.3 & 364.9 & $360 \cdot 2$ & 378.6 & 382.7 & 396.7 & 406.3 & 415.8 & 399.4 \\
\hline \multirow{2}{*}{\multicolumn{13}{|c|}{$\mathrm{Fe}(\mathrm{mg})$}} \\
\hline & & & & & & & & & & & & \\
\hline Mean & 5.4 & $5 \cdot 3$ & 5.4 & 5.5 & 5.7 & 5.5 & 5.5 & $5 \cdot 3$ & $5 \cdot 3$ & $5 \cdot 2$ & $5 \cdot 1$ & 5.0 \\
\hline $95 \% \mathrm{Cl}$ & $5 \cdot 3,5 \cdot 5$ & $5 \cdot 3,5 \cdot 4$ & $5 \cdot 2,5 \cdot 5$ & $5 \cdot 2,5 \cdot 8$ & $5.6,5.9$ & $5 \cdot 3,5 \cdot 7$ & $5 \cdot 2,5 \cdot 7$ & $5 \cdot 1,5 \cdot 5$ & $5 \cdot 1,5 \cdot 4$ & $5 \cdot 1,5 \cdot 4$ & $4 \cdot 9,5 \cdot 3$ & $4 \cdot 3,5 \cdot 6$ \\
\hline
\end{tabular}

ES, general and vocational teaching; AS, agricultural teaching; FFG, food-group frequency guidelines.

Mean values were significantly different between the three levels of compliance with FFG, tested using ANOVA adjusted on the type of menu and number of components: ${ }^{*} P<0.05 ;{ }^{* \star} P<0.01$; ${ }^{* \star *} P<0.001$.

$\dagger$ Reading example: in ES schools with low adequacy to the FFG, a meal provided on average $3225.9 \mathrm{~kJ}$ at lunch. 
response rates observed in studies based on a similar design ${ }^{(26,27)}$. However, representativeness of the sample was verified and information was collected on 22409 meals (16893 lunches and 5516 dinners), which strengthens the present findings. The present study is based on the menus returned by the schools, which implies that the quality of the data relied on the quality of the menu description. Indeed, a large number of cheese and yogurt items in the menu were not precisely identified and were randomly assigned to an amount of $\mathrm{Ca}$ (using the amounts observed for other cheeses or yogurts), which might differ from reality. Furthermore, to ensure the representativeness of the sample, schools with only fifteen menus returned or with free-meal choice were included in the study. Nevertheless, the application of the formula enables the management of this aspect and allows a correct comparison between the offering and the frequency guidelines.

In addition, theoretical portions were used to estimate nutrient amounts in the meals, which might differ from the portions actually served and then eaten by schoolchildren ${ }^{(28)}$. To avoid this issue, in some surveys, food offered and consumption are collected at the same time on school premises ${ }^{(28)}$. This method would enable a better accuracy in the description of the food offered and portion size served but would also require more materials and involve more people to collect the data. It has mainly been used in studies with a small sample of schools, and thus making it difficult to adapt to our large study. Finally, since the recommendations are first to be targeted to the offer, the present study concerned the dietary offer of school meals and did not provide information on the foods chosen by children.

The analysis of meal composition showed that the FFG were well followed for high-fat foods, plant products (raw or cooked vegetables, fruits and starchy foods) and dairy products but not for food groups aimed to improve the nutritional quality of main courses, to promote the consumption of cheese or to limit the consumption of high-sugar desserts. On the whole, the schools appeared to have complied less with the 2007 FFG than the one released in $1999^{(21)}$. This decrease was found for both types of school (ES and AS) and meals (lunch and dinner). Indeed, the 2007 FFG focused on more specific food groups and made stricter demands than the $1999 \mathrm{FFG}^{(21)}$. The differences in compliance between the two versions of the guidelines are mainly explained by the reduction of the maximum FFG defined for food groups to be limited in the earlier guidelines (e.g. high-fat starters), and by the revision of the foods allowed in food groups (e.g. red meat, preparations, fishes, main course with protein:fat ratio). Regarding other food group guidelines, no direct comparison can be made because of the changes and supplementary recommendations made in the 2007 guidelines. However, the new recommendations revealed that the guidelines for fruits in dessert were followed more than those for raw vegetables in starters, and that dairy products were more often proposed than cheeses. The new constraint on total sugar content of fatty desserts in the 2007 guidelines is less restrictive than the previous one and allows more fatty desserts in meals. Thereby, some adjustments are still to be made to improve the recommendations. Following the present study findings, the constraint on sugar content of fatty desserts will be removed in the upcoming regulations.

The nutritional composition analysis confirmed the beneficial effect of FFG on specific nutrient offers, especially when the food group concerned a particular nutrient that should be limited or increased. Thus, food groups aimed at reducing the lipids and total sugar offered favourably influenced the offering for such nutrients. Similarly, the food groups established specifically to increase the offering for $\mathrm{Ca}$, vitamin $\mathrm{C}, \mathrm{Fe}$ and animal proteins were found to be effective on the whole. The decrease in Ca offered when more dairy products are served may be explained by a substitution effect with cheese, which contains greater amounts of $\mathrm{Ca}$ than other dairy products.

Furthermore, the difference in the nutrient offering was robust to adjustment for the number of courses and type of menu, suggesting that they were directly related to compliance with the recommendations rather than reflecting the meal structure.

Differences between lunch and dinner and ES and AS schools were noted. The recommendation impact would appear to be greater for lunch and for ES schools. This difference might be due to the fact that the ES schools and lunch samples were bigger than those for the AS schools and dinner ones.

A comparison between the nutritional offering and general compliance with the recommendations confirmed that high observance of the guidelines tended to lead to a more appropriate global nutrient offering, especially in limiting the energy and fat offered and promoting the vitamin $\mathrm{C}$ offered in school meals. The results confirm the influence of the FFG on the global nutritional offering of school catering. They also suggest that it is necessary to follow all the recommendations to get a balanced diet. Even though no significant evidence of compliance with the general recommendations was observed for dinners, similar trends were found.

Similar benefits of schools meal recommendations have been reported in other studies. Gould et al. ${ }^{(29)}$ have shown that English schools with food provisions closest to the guidelines (mandatory nutritional standards) enabled pupils to benefit from superior nutrient intakes. Two others studies have concluded that the school meal guidelines have the same beneficial effect on the nutritional offering ${ }^{(13-15)}$. However, one study observed a decrease in nutritional intake improvement for the second year. This reversal was explained by students compensating by consuming foods from vending machines rather than (or in addition to) school cafeteria meals during the second year ${ }^{(13,30)}$.

These findings suggest that complementary actions are necessary to provide healthy and nutritious meals at school. Government policies or recommendations for school cafeteria dietary offerings do influence the students' choice of food but they have to be implemented for all food environments (through education on nutrition or changes in the whole school environment (including vending machines)) so that students cannot change to a different source of foods, thus getting around any dietary changes ${ }^{(11,13)}$. The third school 
nutritional dietary assessment in the USA has notably shown a significant reduction in the energy offering from schools that did not have any snack bars or vending machines. The reduction was also observed in schools with unique menus or fewer food choices available in the cafeteria ${ }^{(11)}$. In France, food vending machines have been prohibited ${ }^{(31)}$. It has also been suggested that fruits should be provided free of charge during morning and afternoon breaks as an alternative, to increase their consumption. Meanwhile, other recommendations for morning snacks have been developed in France $^{(32)}$. Consequently, the whole school environment is taken into account. More than merely taking positive measures to foster the access to healthy food or educate children on nutrition and cooking, the French authorities are considering using negative actions such as restricting the food proposition (through FFG) or source of foods at school. Both methods have been found to be complementary and necessary. Nevertheless, the recommendations are first established to balance dietary offering. Thereby, education and training of the person in charge of school meals design is necessary as a first step to success. An international collaborative study has concluded that there is a real and urgent need for national and international health and nutrition programmes to improve the feeding habits of adolescents and help them choose healthier foods ${ }^{(14,15,33,34)}$. Designing effective nutrition interventions for children and appropriate educational strategies is a step forward ${ }^{(35-38)}$ and limiting the temptation is another. The integration of positive measures such as nutritional educational programmes, cooking or garden-based education has been shown to foster healthier eating behaviour ${ }^{(31,36-38)}$ and is necessary to make the restrictive recommendations easy to understand. As the environment has been shown to influence food choices and intake, improvements will also be needed in the dining room, to make school mealtimes a more attractive, social and enjoyable experience ${ }^{(11,29,39-42)}$.

However, even though the effect of recommendations on the nutrients on offer was confirmed, an unbalanced dietary offering in the macronutrients (excess in proteins, fat and lack of carbohydrates) was observed. On the other hand, adequate dietary offerings in $\mathrm{Ca}, \mathrm{Fe}$ and vitamin $\mathrm{C}$ were shown. These findings suggest that improvements are needed to get schools to comply with the FFG by offering students the nutritional requirements. A US study also found similar results, still with excess in fat but with most of the schools following the nutritional requirements for $\mathrm{Ca}, \mathrm{Fe}$ and vitamin $\mathrm{C}$ as well ${ }^{(43)}$.

Moreover, in France, in 2002 a study on meals eaten by children at school found similar results concerning the excess of fat and proteins but better amounts of $\mathrm{Ca}, \mathrm{Fe}$ and vitamin $\mathrm{C}$ from schools meals have been found since ${ }^{(44)}$. This last observation confirms improvements in the dietary offering in school meals over the past few years and the need for compliance with nutritional recommendations. Nevertheless, this last study focused on nutrient intakes whereas our results were based on the nutrients available from the meals proposed. This could also largely explain the improvement in the nutritional offering for $\mathrm{Ca}$, Fe and vitamin C. Hopefully, children's dietary intake in school canteens could be soon estimated from the INCA $2^{(4)}$, and it will then be possible and relevant to confront offering and consumption. Indeed, when given the choice, students generally choose less healthy options. Consequently, better nutritional results are found when the offering is considered than when the analysis concerns food consumed directly by the students ${ }^{(15,45)}$. Furthermore, the present study focused on nutrients that were identified directly associated to one or several FFG. Therefore, this analysis excluded other micronutrients (vitamins and minerals), fibres and saturated fat that were previously shown to be consumed higher in schools meals as compared to home meals ${ }^{(44)}$. On the contrary, $\mathrm{Na}$ intakes were higher in the meals taken at school. Further analyses on dietary intakes at school based on the INCA 2 survey will manage to consider all the nutrient intakes and will enable the trend in dietary intakes over time in French schools to be watched.

\section{Conclusion}

In conclusion, the present study showed that a relatively high proportion of schools followed the FFG. However, improvements are still needed to get a proper and balanced dietary offering for school meals. As these findings confirm the effectiveness and relevance of the recommendations as a way of positively affecting the nutritional offering, full compliance with the FFG will help to improve the dietary offering. Besides, forthcoming legislation based on the last version of FFG drawn up by the GEMRCN in 2007 will compel all caterers to provide healthier meals, which should hopefully increase the compliance of school meals with the recommendations and therefore make their dietary offering healthier.

\section{Acknowledgements}

The present survey was supported by grants from the Ministry of Health within the context of the National Nutrition and Health Programme. It was supervised by a steering committee including the Ministry of Health, Ministry of Agriculture, Ministry of Education, a state high school in Paris and the French Food Safety Agency. There were no conflicts of interest while preparing this paper. M. B. and C. D. designed the study, analysed data and wrote the paper. L. L., J.-L. V. and C. D. designed the survey and contributed to the data collection. G. C.-T. defined the food nomenclature and assigned to the food items collected in the survey to categories in the nomenclature. We are grateful to Ian Margo for revising the manuscript.

\section{References}

1. Dubuisson C, Lioret S, Dufour A, et al. (2010) Socioeconomic and demographic variations in school lunch participation of French children aged 3-17 years. Public Health Nutr 14, 227-238.

2. Direction de l'évaluation, de la prospective et de la performance (Evaluation Planning and Performance Division) (2010) Les établissements (Settlements). In Repères et références statistiques sur les enseignements, la formation et la recherche (Statistical References on Education, Training and Research). Paris: Ministère de l'éducation nationale, 
de l'enseignement supérieur et de la recherché (Ministry of National Education, Higher Education and Research). http://media.education.gouv.fr/file/2010/16/9/RERS_2010_ 152169.pdf

3. French Food Safety Agency (AFSSA) (2009) Enquête INCA2 individuelle et nationale sur les consommations alimentaires des français (French Individual and National Food Consumption Survey INCA2). Paris: French Food Safety Agency (AFSSA). http://www.afssa.fr/Documents/PASER-Ra-INCA2 pdf

4. Birch LL (1998) Development of food acceptance patterns in the first years of life. Proc Nutr Soc 57, 617-624.

5. Birch LL (1999) Development of food preferences. Annu Rev Nutr 19, 41-62.

6. Birch LL \& Fisher JO (1998) Development of eating behaviors among children and adolescents. Pediatrics 101, 539-549.

7. Nicklaus S (2009) Development of food variety in children. Appetite 52, 253-255.

8. Lioret S, Touvier M, Dubuisson C, et al. (2009) Trends in child overweight rates and energy entake in France from 1999 to 2007: relationships with socioeconomic status. Obesity (Silver Spring) 17, 1092-1100.

9. Lioret S, Touvier M, Lafay L, et al. (2008) Dietary and physical activity patterns in French children are related to overweight and socioeconomic status. J Nutr 138, 101-107.

10. Kramer-Atwood JL, Dwyer J, Hoelscher DM, et al. (2002) Fostering healthy food consumption in schools: focusing on the challenges of competitive foods. J Am Diet Assoc 102, 1228-1233.

11. Briefel RR, Crepinsek MK, Cabili C, et al. (2009) School food environments and practices affect dietary behaviors of US public school children. J Am Diet Assoc 109, S91-S107.

12. Briefel RR, Wilson A \& Gleason PM (2009) Consumption of low-nutrient, energy-dense foods and beverages at school, home, and other locations among school lunch participants and nonparticipants. J Am Diet Assoc 109, S79-S90.

13. Cullen KW, Watson K, Zakeri I, et al. (2006) Exploring changes in middle-school student lunch consumption after local school food service policy modifications. Public Health Nutr 9, 814-820.

14. Vereecken CA, Bobelijn K \& Maes L (2005) School food policy at primary and secondary schools in BelgiumFlanders: does it influence young people's food habits? Eur J Clin Nutr 59, 271-277.

15. Nelson M, Lowes K \& Hwang V (2007) The contribution of school meals to food consumption and nutrient intakes of young people aged $4-18$ years in England. Public Health Nutr 10, 652-662.

16. Czernichow S \& Martin A (2000) Nutrition et restauration scolaire, de la maternelle au lycée: états des lieux (Nutrition and School Meals, from Kindergarten to High School: Status). Paris: French Food Safety Agency (AFSSA). http:// www.afssa.fr/Documents/PASER-Ra-Restoscolaire2000.pdf

17. Lafay L, Volatier JL \& Martin A (2002) La restauration scolaire dans l'enquête INCA - associations entre facteurs socio-démographiques, mode de vie et fréquentation de la restauration scolaire (1ère partie) (School meals in the INCA survey - associations between socio-demographic, lifestyle and attendance of school meals (Part 1)). Cab Nutr Diét 37, 36-44.

18. Dubuisson C, Lioret S, Calamassi-Tran G, et al. (2009) School meals in French secondary state schools with regard to the national recommendations. Br J Nutr 102, 293-301.

19. French Food Safety Agency (AFSSA) (2007) Evaluation de la connaissance et de l'application de la circulaire du 25 juin
2001 relative à la composition des repas servis et à la sécurité des aliments dans les établissements publics du second degré (2005-2006) (Assessment of Knowledge and Application of the Circular of 25 June 2001 on School Meal Composition and Food Safety in Secondary State Schools (2005-2006)). Paris: AFSSA. http://www.afssa.fr/Documents/PASER-RaRestoScol2007.pdf

20. Groupe d'Etude des Marchés de Restauration Collective et Nutrition (Study Group Markets Catering and Nutrition) (GEMRCN) (2007) Recommandation relative à la nutrition du 4 mai 2007 (Recommendation on the nutrition of May 4, 2007). In Rapport de l'Observatoire Economique de l'Achat Public du ministère de l'Economie, des finances et de l'industrie (Report of the Economic Observatory for Public Procurement of the Ministry of Economy, Finance and Industry). http://www.minefi.gouv.fr/directions_services/daj/ guide/gpem/nutrition/nutrition.htm

21. Groupe permanent d'étude des marchés de denrées alimentaires (Standing Group for the Study of food markets) (1999) Recommandations du groupe permanent d'étude des marchés de denrées alimentaires (GPEM/DA) relative à la nutrition (Recommendations of the standing group for the study of food markets (GPEM/DA) on nutrition). In Brochure JO de la direction des Affaires juridiques du ministère de l'Economie, des finances et de l'industrie (Official Journal of the Legal Affairs Department of the Ministry of Economy, Finance and Industry). http://www.education.gouv.fr/bo/ 2001/special9/annexe.htm

22. Hercberg S, Chat-Yung S \& Chauliac M (2008) The French National Nutrition and Health Program: 2001-2006-2010. Int J Public Health 53, 68-77.

23. Favier JC, Ireland-Ripert J, Toque C, et al. (1995) Répertoire général des aliments - Table de composition (Food Composition Table), 2nd ed. Paris: Lavoisier.

24. Sautory O (1993) La macro CALMAR - Redressement d'un échantillon par calage sur marges (The Macro CALMAR Sample Calibration Adjustment on Margins). Paris: INSEE. http://www.insee.fr/fr/methodes/outils/calmar/doccalmar. pdf

25. Bertin M, Lafay L, Calamassi-Tran G, et al. (2010) La restauration scolaire dans les établissements publics français du second degré: respect des recommandations nationales et profils d'établissements (School meals in French secondary state schools: compliance with national recommendations and schools catering pattern). Rev Epidemiol Sante Publique 59, 33-44.

26. Vereecken CA, Bobelijn K \& Maes L (2005) School food policy at primary and secondary schools in BelgiumFlanders: does it influence young people's food habits? Eur J Clin Nutr 59, 271-277

27. French SA, Story M \& Fulkerson JA (2002) School food policies and practices: a state-wide survey of secondary school principals. J Am Diet Assoc 102, 1785-1789.

28. Food Standard Agency (2004) Schools Meals in Secondary Schools in England. Research Report RR557. London: Food Standard Agency. http://www.dfes.gov.uk/research/data/ uploadfiles/RR557.pdf

29. Gould R, Russell J \& Barker ME (2006) School lunch menus and 11 to 12 year old children's food choice in three secondary schools in England - are the nutritional standards being met? Appetite 46, 86-92.

30. Neumark-Sztainer D, Story M, Perry C, et al. (1999) Factors influencing food choices of adolescents: findings from focus-group discussions with adolescents. I Am Diet Assoc 99, 929-937. 
31. Martin A (2005) La place de la nutrition dans les établissements scolaires (The role of nutrition in schools). Cab Nutr Diét 40, 81-86.

32. Lafay L, Boclé JC, Kalonji E, et al. (2004) La collation matinale: fréquence, composition alimentaire et impact sur la nutrition des enfants (The morning snack frequency, diet composition and impact on child nutrition). Cab Nutr Diét 39, 401-408.

33. Howerton MW, Bell BS, Dodd KW, et al. (2007) Schoolbased nutrition programs produced a moderate increase in fruit and vegetable consumption: meta and pooling analyses from 7 studies. J Nutr Educ Behav 39, 186-196.

34. Vereecken CA, De Henauw S \& Maes L (2005) Adolescents' food habits: results of the health behaviour in school-aged children survey. BrJ Nutr 94, 423-431.

35. Hoelscher DM, Evans A, Parcel GS, et al. (2002) Designing effective nutrition interventions for adolescents. $\mathrm{J} \mathrm{Am} \mathrm{Diet}$ Assoc 102, S52-S63.

36. Perez-Rodrigo C \& Aranceta J (2003) Nutrition education in schools: experiences and challenges. Eur J Clin Nutr 57, Suppl. 1, S82-S85.

37. Hyland R, Stacy R, Adamson A, et al. (2006) Nutrition-related health promotion through an after-school project: the responses of children and their families. Soc Sci Med 62 , $758-768$.
38. Robinson-O'Brien R, Story M \& Heim S (2009) Impact of garden-based youth nutrition intervention programs: a review. J Am Diet Assoc 109, 273-280.

39. Birch LL (1998) Psychological influences on the childhood diet. J Nutr 128, 407S-410S.

40. Fisher JO \& Birch LL (1999) Restricting access to foods and children's eating. Appetite 32, 405-419.

41. Fisher JO \& Birch LL (1999) Restricting access to palatable foods affects children's behavioral response, food selection, and intake. Am J Clin Nutr 69, 1264-1272.

42. Story M, Neumark-Sztainer D \& French S (2002) Individual and environmental influences on adolescent eating behaviors. J Am Diet Assoc 102, S40-S51.

43. Crepinsek MK, Gordon AR, McKinney PM, et al. (2009) Meals offered and served in US public schools: do they meet nutrient standards? J Am Diet Assoc 109, S31-S43.

44. Lafay L, Volatier JL \& Martin A (2002) La restauration scolaire dans l'enquête INCA-les repas servis en restaurations scolaires: apports nutritionnels, alimentaires et impact sur la nutrition des enfants (School meals in the survey INCAmeals served in school canteens: nutritional, dietary and nutritional impact on children). Cah Nutr Diét 37, 395-404.

45. Fox MK, Gordon A, Nogales R, et al. (2009) Availability and consumption of competitive foods in US public schools. J Am Diet Assoc 109, S57-S66. 